\title{
Glucocorticoids and breast cancer risk
}

\author{
Kelly A. Hirko ${ }^{1^{*}}$ and A. Heather Eliassen ${ }^{2,3}$
}

Keywords: Glucocorticoids, Breast cancer, Estrogen receptor

\section{Background}

Glucocorticoids are essential endogenous steroid hormones secreted in response to stress, and treatment with synthetic forms is widespread for numerous inflammatory conditions including asthma, chronic obstructive pulmonary disease, inflammatory bowel disease, and arthritis [1]. Emerging evidence suggests that glucocorticoids can exert both anti- and pro-inflammatory effects, modulated through suppressing or augmenting immune response [1]. Given these divergent biologic properties, glucocorticoids could theoretically reduce breast cancer risk via anti-inflammatory effects or could increase breast cancer risk and progression by inducing insulin resistance and promoting immunosuppression [2]. Yet, despite biological plausibility, epidemiologic studies of glucocorticoid use and breast cancer are limited.

\section{New data}

As such, the recent prospective cohort study by Cairat et al. [3] is an important contribution to the literature as an investigation into the potential role of glucocorticoids in breast cancer etiology. In this study, authors evaluated associations between glucocorticoid use and breast cancer risk among over 65,000 postmenopausal French women in the E3N cohort. Using linkage to outpatient health expenditures, authors observed that receipt of at least two reimbursements of systemic glucocorticoids was associated with a reduced risk of invasive breast cancer, which appeared to follow a dose-response trend with increasing number of reimbursements. The observed

This comment refers to the article available at https://doi.org/10.1186/ s12916-021-02004-6.

* Correspondence: hirkokel@msu.edu

'Department of Epidemiology and Biostatistics, College of Human Medicine, Michigan State University, 909 Fee Road, East Lansing, Ml 48824, USA

Full list of author information is available at the end of the article associations did not differ substantially by type of glucocorticoid, or by timing or duration of use. However, inverse associations were significant only among women older than 60 years at first use. In stratified analyses, the inverse associations were restricted to estrogen receptor (ER)-positive tumors, and stage I and II disease. Interestingly, authors also observed positive associations between glucocorticoids and risk of in situ breast cancer and stage III/IV breast cancer, although confidence intervals for these measures of association were wide given smaller numbers of cases. In sensitivity analysis, only recurrent users (not occasional users) were at higher risk of in situ or stage III or IV disease and only recurrent users were at lower risk of stage I or II breast cancer. The authors conclude that the association between systemic glucocorticoid use and breast cancer risk may differ by tumor subtypes and stage of disease.

Unlike prior studies, Cairat et al. were able assess whether the associations of glucocorticoids and breast cancer differed according to hormone receptor status, histological subtype, tumor grade, and stage at diagnosis. This is particularly important given the various pharmacological properties of glucocorticoids and evidence for cross-talk between estrogen receptors and glucocorticoid receptors in mammary epithelial cells [4], which suggests that glucocorticoids could differentially impact breast cancer subtypes. An additional strength of this study was the inclusion of comprehensive information on potential confounders including body mass index, alcohol consumption, family history of breast cancer, and use of nonsteroidal anti-inflammatory medication; factors which were not considered in prior population registry-based studies in Denmark $[5,6]$ where no associations between receipt of glucocorticoid prescription and breast cancer risk were observed. 
This study is informative in teasing apart heterogeneity in glucocorticoid-breast cancer associations by hormone receptor status to isolate the potential impact of estrogen pathways. As authors of this study note, estrogen inhibition induced by glucocorticoids may explain the lower risk of ER-positive tumors observed in this study. Moreover, given that ER-positive tumors tend to be less aggressive than ER-negative tumors, the inverse associations observed for early stage disease may reflect the preponderance of ER-positive tumors in this group. Systemic glucocorticoid use also affects immune system function and insulin sensitivity, which could induce adipose aromatase activity and estrogen production and also directly stimulate breast cancer cell growth and invasion [7], thereby facilitating breast cancer progression and later stage of disease at diagnosis. However, biological plausibility for the observed positive association between glucocorticoids and in situ disease is less clear. Although a possible explanation for this finding may be increased surveillance for women prescribed glucocorticoids, the results were similar when restricted to women with a recent mammogram. Further, that the increased risk of in situ disease corresponds with findings for later, but not earlier, stage invasive disease, is not likely to be explained by surveillance bias, but also complicates the biological plausibility of these findings. The conflicting findings in this study underscore the need for continued research to elucidate the complex interactions between chronic inflammation, obesity, and insulin resistance in breast cancer.

\section{Impact and implications}

The potential impact of these findings are substantial, given the widespread and increasing use of glucocorticoids over the past several decades $[8,9]$, and the extensive global breast cancer burden with an estimated 2.3 million new cases diagnosed in 2020 [10]. However, it should be emphasized that research on the impact of glucocorticoids and breast cancer risk is still in a nascent stage. Indeed, this is the first study to evaluate whether the relationship between glucocorticoids and breast cancer differs according to hormone receptor status, histology, and tumor stage. Thus, results need to be confirmed in large epidemiologic studies with detailed information on tumor characteristics to address the small number of in situ, ER-negative, and late stage breast cancers included in the current study. If findings are confirmed in future studies, clinical implications will also need to consider both the risks and benefits of glucocorticoid use in clinical care.

\section{Conclusions}

In conclusion, this study's findings are intriguing and merit follow-up to further characterize the potential role of glucocorticoids and other anti-inflammatory therapies in breast cancer etiology. Specifically, future studies recognizing the complex interplay between inflammation and adaptive immune response in breast cancer are needed to inform our understanding of etiology and the development of personalized medicine approaches in breast cancer.

\section{Acknowledgements \\ None}

Authors' contributions

All authors contributed to the writing of the manuscript and approved the final manuscript.

\section{Funding}

None

Availability of data and materials

Not applicable

\section{Declarations}

Ethics approval and consent to participate

Not applicable

Consent for publication

Not applicable

\section{Competing interests}

The authors declare that they have no competing interests.

\section{Author details}

'Department of Epidemiology and Biostatistics, College of Human Medicine, Michigan State University, 909 Fee Road, East Lansing, MI 48824, USA.

${ }^{2}$ Department of Epidemiology, Harvard T.H. Chan School of Public Health, Boston, MA, USA. ${ }^{3}$ Channing Division of Network Medicine, Department of Medicine, Brigham and Women's Hospital and Harvard Medical School, Boston, MA, USA.

Received: 14 June 2021 Accepted: 14 June 2021

Published online: 02 August 2021

\section{References}

1. Cruz-Topete D, Cidlowski JA. One hormone, two actions: anti- and proinflammatory effects of glucocorticoids. Neuroimmunomodulation. 2015; 22(1-2):20-32. https://doi.org/10.1159/000362724.

2. McNamara KM, Kannai A, Sasano H. Possible roles for glucocorticoid signalling in breast cancer. Mol Cell Endocrinol. 2018;466:38-50. https://doi. org/10.1016/j.mce.2017.07.004

3. Cairat M, Al Rahmoun M, Gunter MJ, et al. Use of systemic glucocorticoids and risk of breast cancer in a prospective cohort of postmenopausal women (in press). BMC Med. 2021.

4. Kinyamu HK, Archer TK. Estrogen receptor-dependent proteasomal degradation of the glucocorticoid receptor is coupled to an increase in mdm2 protein expression. Mol Cell Biol. 2003;23(16):5867-81. https://doi. org/10.1128/MCB.23.16.5867-5881.2003.

5. Sørensen HT, Mellemkjaer L, Skriver MV, et al. NO excess risk of breast cancer among female users of systemic glucocorticoids. Cancer Epidemiol Biomark Prev Publ Am Assoc Cancer Res Cosponsored Am Soc Prev Oncol. 2005;14(4):1022-3. https://doi.org/10.1158/1055-9965.EPI-04-0488.

6. Sørensen GV, Cronin-Fenton DP, Sørensen HT, Ulrichsen SP, Pedersen L, Lash TL. Use of glucocorticoids and risk of breast cancer: a Danish population-based case-control study. Breast Cancer Res. 2012;14(1):R21. https://doi.org/10.1186/bcr3106.

7. Rose DP, Gracheck PJ, Vona-Davis L. The interactions of obesity, inflammation and insulin resistance in breast cancer. Cancers. 2015:7(4): 2147-68. https://doi.org/10.3390/cancers7040883. 
8. Laugesen K, Jørgensen JOL, Petersen I, Sørensen HT. Fifteen-year nationwide trends in systemic glucocorticoid drug use in Denmark. Eur J Endocrinol. 2019;181(3):267-73. https://doi.org/10.1530/EJE-19-0305.

9. Overman RA, Yeh J-Y, Deal CL. Prevalence of oral glucocorticoid usage in the United States: a general population perspective. Arthritis Care Res. 2013; 65(2):294-8. https://doi.org/10.1002/acr.21796.

10. Sung H, Ferlay J, Siegel RL, Laversanne M, Soerjomataram I, Jemal A, et al. Global cancer statistics 2020: GLOBOCAN estimates of incidence and mortality worldwide for 36 cancers in 185 countries. CA Cancer J Clin. 2021; 71(3):209-49. https://doi.org/10.3322/caac.21660

\section{Publisher's Note}

Springer Nature remains neutral with regard to jurisdictional claims in published maps and institutional affiliations.

Ready to submit your research? Choose BMC and benefit from:

- fast, convenient online submission

- thorough peer review by experienced researchers in your field

- rapid publication on acceptance

- support for research data, including large and complex data types

- gold Open Access which fosters wider collaboration and increased citations

- maximum visibility for your research: over $100 \mathrm{M}$ website views per year

At $\mathrm{BMC}$, research is always in progress.

Learn more biomedcentral.com/submissions 